\section{Commentary: The ABC's of donation after circulatory death heart transplantation}

\author{
Jason J. Han, MD, Amit Iyengar, MD, and \\ Pavan Atluri, MD
}

More than 250,000 people in the United States currently live with end-stage heart failure and would benefit from heart transplantation in the near future. ${ }^{1}$ Donor organ shortage remains the most critical issue facing modern heart transplantation, and with constantly improving transplant outcomes, all creative and ambitious means of donor pool expansion warrant our attention. In the United States, almost all heart transplants are procured from donors who meet complete brain death criteria (donation after brain death). Alternatively, donation after circulatory death (DCD) donors characterize an additional set of donors in whom full brain-death criteria is not met, but support is withdrawn until cessation of circulation occurs (Maastricht category III). The Institute of Medicine has pushed for the expansion of DCD organ utilization for more than a decade, and remarkable progress has been made in other areas of solid organ transplantation. ${ }^{2,3}$

In consideration of expansion toward cardiac allografts, considerable hesitation has plagued DCD heart transplantation given the process involves withdrawal of life support with concern for considerable warm ischemic injury and need for reanimation of the heart on cardiopulmonary bypass or with relatively novel ex vivo perfusion devices. Furthermore, ethical considerations of defining cardiac death have been raised when considering use of a DCD heart. However, DCD heart transplantation has enormous potential if fully realized, and may raise overall heart transplant volume by as much as $30 \%$ by some estimates. It is at this opportune time in the field of transplantation

\footnotetext{
From the Division of Cardiovascular Surgery, Department of Surgery, University of Pennsylvania, Philadelphia, Pa.

Disclosure: Authors have nothing to disclose with regard to commercial support.

Received for publication Feb 26, 2020; revisions received Feb 26, 2020; accepted for publication Feb 27, 2020; available ahead of print March 19, 2020.

Address for reprints: Pavan Atluri, MD, Division of Cardiovascular Surgery, Department of Surgery, Hospital of the University of Pennsylvania, 3400 Spruce St, 6 Silverstein Pavilion, Philadelphia, PA 19072 (E-mail: Pavan.Atluri@uphs.upenn. edu).

J Thorac Cardiovasc Surg 2021;161:1341-2

$0022-5223 / \$ 36.00$

Copyright (c) 2020 by The American Association for Thoracic Surgery https://doi.org/10.1016/j.jtcvs.2020.02.122
}

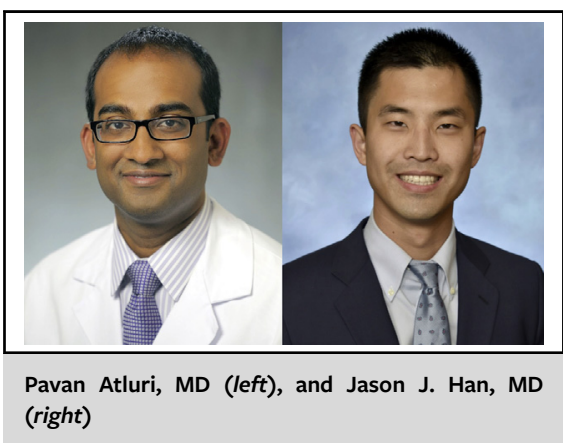

CENTRAL MESSAGE

Donation after circulatory death

is growing in prevalence and of-

fers a viable alternative to dona-

tion after brain death heart

transplantation.

that Rajab and colleagues ${ }^{4}$ published their expert review. The authors' approach is holistic in its consideration of the historical context, surgical techniques, as well as the ethical complexities and controversies therein. Understanding DCD heart transplantation from its elemental ABCs is compulsory in moving the field forward, and the authors highlight these points concisely. As a select few hospitals in the United States have begun to perform adult DCD heart transplantation with the Transmedics OCS device (Transmedics, Andover, Mass), we are seeing history being made.

The interdisciplinary discussion Rajab and colleagues ${ }^{4}$ bring is particularly important as advancement in the area of DCD relies on a carefully coordinated effort between the clinical and the ethical, involving not only the conduct of the operation but also the legal framework. Notably, the field is still in the stage of fine-tuning its identity. Some would contend the more accurate description of DCD is circulatory death rather than cardiac death-which lingers in terminology from eras before advanced mechanical circulatory support. ${ }^{5}$ This small difference in phrasing has readily appreciable differences in inherent meaning when considering the ethics of cardiac allograft utilization and the definition of death. Progress forward is never easy and will require continued efforts. The words we choose and our ethical framework are essential in fully realizing DCD heart transplantation.

Ultimately, the authors deserve our heartfelt congratulations for an important contribution to a budding arena. The ABCs of DCD are no longer futuristic-we enthusiastically look forward to continued exploration and 
expansion of DCD heart transplantation in the United States.

\section{References}

1. Depasquale EC, Schweiger M, Ross HJ. A contemporary review of adult heart transplantation: 2012 to 2013. J Heart Lung Transplant. 2014;33:775-84.

2. Institute of Medicine. Organ Donation: Opportunities for Action. Washington, DC: The National Academies Press; 2006.
3. Smith M, Dominguez-Gil B, Greer DM, Manara AR, Souter MJ. Organ donation after circulatory death: current status and future potential. Intensive Care Med. 2019;45:310-21.

4. Rajab TK, Jaggers J, Campbell DN. Heart transplantation following donation after cardiac death: history, current techniques, and future. J Thorac Cardiovasc Surg. 2021;161:1335-40.

5. Page A, Messer S, Large SR. Heart transplantation from donation after circulatory determined death. Ann Cardiothorac Surg. 2018;7:75-81.
See Article page 1335 .

\section{Commentary: The future is now- heart donation after circulatory death}

\author{
Zachary N. Kon, MD, Deane E. Smith, MD, \\ Julius A. Carillo, MD, and Nader Moazami, MD
}

In this issue of the Journal, Rajab and co-authors ${ }^{1}$ review the historical perspective, current techniques, and possible future directions of heart donation after circulatory death (DCD). The historical perspective is particularly relevant to this topic, as previous attempts to initiate a successful clinical program without first evaluating and defending the ethical ramifications set the field back more than a decade in the United States. In fact, as the authors point out, it previously led to homicide allegations against physicians. ${ }^{2}$ The idea of dealing with ethical concerns in the future is unwise and must be evaluated and solved before initiation of any clinical application. To that end, our group has recently published an article thoroughly exploring this topic. ${ }^{3}$ We believe it appropriately defended the ethical and legal permissibility of the practice before our first clinical case. Additionally, independent of true ethical concerns, national, regional, and local acceptance is paramount for the successful future of this field. All of these will need to be continuously appraised and solved as

From the Department of Cardiothoracic Surgery, NYU Langone Health, New York, NY.

Disclosures: Authors have nothing to disclose with regard to commercial support. Received for publication March 5, 2020; revisions received March 5, 2020; accepted for publication March 5, 2020; available ahead of print March 20, 2020.

Address for reprints: Zachary N. Kon, MD, 530 First Ave, Suite 9V, New York, NY 10016 (E-mail: Zachary.kon@ nyulangone.org).

J Thorac Cardiovasc Surg 2021;161:1342-3

$0022-5223 / \$ 36.00$

Copyright $(\odot 2020$ by The American Association for Thoracic Surgery

https://doi.org/10.1016/j.jtcvs.2020.03.037
Check for updates

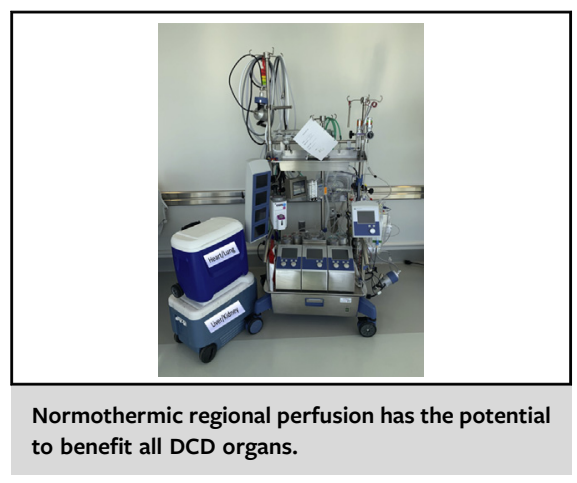

CENTRAL MESSAGE

The ethical and logistical con-

structs should dictate the future

direction of heart DCD and must

include consideration for all

transplant organs, not just hearts.

more experience with DCD heart transplantation matures. However, again, waiting until it is a problem is not the solution.

Although multiple options for DCD heart donation are possible, they are not all equal. Direct transplantation without in situ or ex situ perfusion evaluation has not been done with any meaningful frequency in the last decade, and there is no reason to think that there will be any resurgence given the other technologies. A direct comparison between normothermic regional perfusion (NRP) and ex situ perfusion approaches is important. First, as with transplantation in general, the acceptance rate of each approach can be variable. Based on the United Kingdom $^{4}$ and Australian ${ }^{5}$ experiences, ex situ perfusion yielded a $77.7 \%$ and $69.7 \%$ use rate, respectively. In contrast, the UK experience with NRP with subsequent ex situ perfusion increased the yield to $100 \%$ of assessed 